\title{
SABERES NECESSÁRIOS À EDUCAÇÃO PROFISSIONAL E TECNOLÓGICA: DESAFIOS DA FORMAÇÃO DOCENTE E A NECESSIDADE DA ARTICULAÇÃO TEORIA-PRÁTICA
}

\author{
KNOWLEDGE NECESSARY FOR PROFESSIONAL AND \\ TECHNOLOGICAL EDUCATION: CHALLENGES OF TEACHER \\ TRAINING AND THE NEED FOR THEORY-PRACTICE
}

\author{
Elison Victor Braga da Silva ${ }^{11}$ \\ Shauanda Stefhanny Leal Gadêlha Fontes ${ }^{12}$ \\ José Araújo Amaral ${ }^{13}$
}

A atuação do professor é uma temática de relevância no contexto da educação do Brasil. O docente é tido como um dos principais agentes do processo formativo dos cidadãos. Essa percepção, que valoriza a figura do educador, responsabiliza os docentes para que se cerquem de variados conhecimentos para possibilitar aos estudantes, a partir do processo de mediação, os meios necessários à reflexão crítica a respeito dos aspectos: cultural, social, econômico e também político.

Ao fazer menção à maneira que o educador deve se posicionar em relação aos estudantes, Arroyo (2013) considera que os saberes e competências que são ensinados na infância ou na adolescência têm implicações na vida pessoal e também na sociedade, na economia e na política, e que não é prudente acreditar que os docentes formam personalidades plenas para se contemplar, para ter uma compreensão positiva de si, isoladas da sua situação real e de sua inserção histórica, social e também política.

\footnotetext{
${ }^{11}$ Bacharel em Engenharia Civil (UnP). Mestrando do Programa de Pós-graduação em Educação Profissional e Tecnológica - ProfEPT (IFRN). E-mail: elisonvictorbraga@ hotmail.com.

${ }^{12}$ Bacharela em Administração (UFPI). Mestranda do Programa de Pós-graduação em Educação Profissional e Tecnológica - ProfEPT (IFRN). E-mail: shauandalealfontes@gmail.com.

${ }^{13}$ Graduado em Ciências Biológicas (USP); Mestre e Doutor em Biotecnologia (USP). Professor do Instituto Federal de Educação, Ciência e Tecnologia do Rio Grande do Norte (IFRN)/Campus Mossoró. E-mail: jose.amaral@ifrn.edu.br.
} 
O educador contemporâneo não é apenas um transmissor de conteúdo, e esse profissional deve ser percebido de maneira ampla e de modo que o exercício da atividade docente seja enxergado como uma das partes principais do processo de construção dos indivíduos. Em Pedagogia da Autonomia, Freire (1996) já apontava que ensinar não era transferir conhecimento, mas criar possibilidades para sua construção e produção.

Espera-se do professor mais do que o simples compartilhamento de conteúdo sistematizados. Pretende-se que ele aja como um fomentador de reflexões e que suas ações e práticas pedagógicas levem em consideração os saberes científicos. Ademais, espera-se também que considerem os conhecimentos prévios dos alunos e que reconheçam as particularidades de cada um. Dessa forma, é possível atingir o coletivo e contribuir, ao longo do processo formativo, com o aprimoramento do senso crítico dos educandos.

Ao discorrer sobre as abordagens do ensino, Mizukami (1986) aponta que toda ação educativa é considerada apropriada quando antecede a reflexão sobre o homem e aprecia o meio de vida desse indivíduo. A ação educativa deve priorizar a quem se quer ajudar para que se eduque!!! A carência da reflexão sobre o homem acarreta a redução de métodos educativos e de diretrizes emancipadoras, limitando o indivíduo à condição de objeto. $\mathrm{Na}$ busca por rejeitar tal objetificação, o professor deve transformar a função docente no ato de educar, confrontando, em suas ações pedagógicas, diferentes visões de mundo e concepções científicas, visando a construção de sujeitos autônomos capazes de ler criticamente a realidade (FRIGOTTO, 2017).

A função do docente transformador ultrapassa as fronteiras da formação técnicocientífica e atinge os processos formativos sociais do homem colaborando para o desenvolvimento integral e politécnico. O professor deve assumir uma responsabilidade ético-política ao desempenhar a sua função, de tal modo que a educação seja vista como um meio possível para a transformação concreta da sociedade (MORAIS; HENRIQUE, 2014).

É necessário apontar que ao longo da história brasileira, essa educação, mobilizada pela possível transformação dos indivíduos, se manteve longe de se tornar efetiva, pois no decorrer do tempo, com poucas exceções, o ensino foi usado como um instrumento de manutenção do poder opressor. Uma educação transformadora deve pressupor, como política de Estado, investimento público adequado, sensibilidade gestora para inovação 
pedagógica, e, evidentemente, valorização dos educadores e funcionários envolvidos no sistema.

Nos últimos dezoito anos, a Educação Profissional e Tecnológica (EPT), principalmente no âmbito da Rede dos Institutos Federais, foi ampliada, obteve um investimento substancial em estrutura e recursos humanos, e despontou como um ambiente favorável e eficiente para se desenvolver uma formação discente que contemple as mais variadas dimensões que norteiam os indivíduos.

Assim, considerando este ambiente favorável à EPT, em sua vertente formativa integral, percebe-se que a discussão da temática sobre os Saberes Docentes, com foco nesta modalidade educativa, é academicamente relevante, pois, em última instância, traz à tona o debate sobre como um docente com formação apropriada pode contribuir adequadamente para o processo formativo de cidadãos e trabalhadores que tenham uma percepção de mundo apurada. Desta forma, o presente capítulo visiona refletir sobre a seguinte questão reflexiva: Quais os desafios encontrados pelos professores no que diz respeito a formação necessária para a atuação na EPT?

Metodologicamente, esse estudo qualitativo (YIN, 2016), de natureza exploratóriaexplicativa (GIL, 2007), materializado por meio de uma revisão de literatura, parte da análise de outros estudos existentes, cuja a produção se embasa em artigos, livros, capítulos de livros e também em trabalhos publicados a partir de eventos cujas temáticas correspondem ao assunto. Os artigos foram identificados a partir das bases de dados da Revista Brasileira de Educação Profissional e Tecnológica (RBEPT), Scientific Electronic Library Online (SciELO) e também por meio do Google Acadêmico. Essa pesquisa foi realizada entre os meses de fevereiro e maio de 2020 e levou em consideração os seguintes descritores: educação profissional e tecnológica, formação de professores, prática educativa e saber docente.

Em linhas gerais, o capítulo tomo como propósito central o apontamento dos desafios encontrados pelos professores para alcançar a formação docente necessária para a atuação na Educação Profissional e Tecnológica (EPT). Como objetivos específicos foram estabelecidos os seguintes propósitos: a) Descrever a importância do papel do professor no processo formativo e na emancipação humana de estudantes da EPT, b) Discutir sobre os desafios de uma formação docente específica para a atuação na EPT e c) Refletir a respeito da importância das relações teórico-práticas nas atividades docentes na EPT. 


\section{A FORMAÇÃO DOCENTE SÓLIDA COMO UMA AQUISIÇÃO POTENTE}

Dentre as diversas discussões que têm ocorrido, nos últimos anos, em relação à construção dos saberes docentes, muito se questiona a respeito da formação do professor, pois esta tem sido apontada como "deficitária". Durante o processo de formação, esses profissionais são conduzidos por conteúdos e teorias que, por vezes, não dialogam com a realidade com a qual irão se deparar em sala de aula. O que se deseja é uma formação sólida, onde a teoria esteja alinhada com a prática pois o professor precisa combinar os elementos teóricos com situações possíveis de serem aplicadas (LIBÂNEO; PIMENTA, 1999 apud LEIVA; SINÉSIO; CORRÊA, 2019).

A maneira como os docentes traçam o seu processo formativo implica, e muito, na forma como os mesmos irão conduzir as discussões nas salas de aulas pois os saberes que os professores acumulam ao longo da vida estão ligados à sua formação científica, às experiências de vida e à percepção que eles têm em relação ao mundo e às pessoas. Verdum (2013, p. 92) corrobora com essa perspectiva ao apontar que: "a trajetória pessoal e profissional são fatores definidores dos modos de atuação do professor, revelando suas concepções sobre o fazer pedagógico".

Tomando por base essa mesma percepção, Nóvoa (2004) aponta que os educadores devem agir com a intenção de emancipar. Nessa ótica, faz-se necessário que os professores percebam a importância de dialogar os conteúdos ministrados com a prática, de se cercarem a respeito dos mais variados conhecimentos, de forma que seja possível alcançar a realidade dos seus alunos e contribuir também para o desenvolvimento desses cidadãos.

O professor foi visto, durante muito tempo, como aquele que faz a transmissão de conhecimentos aos educandos, ou seja, como pessoa detentora do saber e que tem o dever de ensinar àqueles que "não sabiam". No entanto, embora os educadores possuam saberes, é possível constatar que eles não são os únicos que têm a posse, tendo em vista que Freire (1996) ao dizer que o ensino exige respeito aos saberes dos educandos, já deixava claro que é essencial que os docentes considerem o contexto social em que os alunos estão inseridos e os saberes que cada aluno carrega, e que esses conhecimentos prévios, adquiridos no 
cotidiano, aliados ao conhecimento científico são fundamentais para a formação dos sujeitos.

Devido às lutas docentes pela melhoria no ensino e em contraposição às ideias tradicionalistas de educação, o papel do docente passou por um processo de ressignificação. Hoje o professor é compreendido como um agente de mediação, capaz de colaborar, por meio de suas práticas pedagógicas e educativas, com a construção dos conhecimentos dos alunos, de modo que estes aprendam a pensar de maneira crítica e estabeleçam suas próprias convicções (BULGRAEN, 2010).

Contribuindo com essa discussão, Tardif (2005) defende a existência de dois tipos de saberes como constituintes do docente, sendo o que ele chamou de "o saber fazer e o saber ser". O autor defende que ambos são alcançados tanto no processo de formação básica dos professores (graduação) como no exercício prático de suas profissões (prática docente), de modo que os dois podem ser compreendidos como fomentadores dos processos de formação e aprendizagem.

A tarefa do educador não é transferir, depositar e nem oferecer conhecimento para o seu aluno, tomando-o como paciente da sua forma de pensar. Em detrimento dessas ações, a missão do docente é exercer, como ser humano, a prática de auxiliar os alunos a usarem a inteligência para que possam compreender os assuntos e desafiar o educando com quem se comunica para produzir conhecimento e para alargar a habilidade comunicativa (FREIRE, 1996).

A educação deve inspirar conhecimentos, assim como comportamentos éticos, práticas sociais e habilidades que facilitem o vínculo que existe entre o homem e o mundo. Isso envolve as diversas esferas que norteiam os seres e as relações humanas, especialmente, as dimensões cultural e social. O sistema educacional deve colaborar com a transformação das pessoas, possibilitando modificações desejáveis e relativamente permanentes, isso implica na aquisição de novas condutas e mudanças das que já existem (MIZUKAMI, 1986).

A ação docente alicerça a formação escolar dos sujeitos, contribuindo para a construção de uma sociedade que pensa e age criticamente. Entretanto, para que tal afirmativa seja possível é necessário que o professor estabeleça em si um processo de identificação com suas atribuições, ou seja, o educador precisa assumir as responsabilidades 
e os compromissos da profissão, tomando consciência do seu papel, enquanto agente de transformação social (FREIRE, 1996).

Desse modo, é necessário se discutir o papel do professor e do aluno, a forma como eles se relacionam nos espaços formativos educacionais e de que maneira essa interação colabora para o crescimento intelectual dos sujeitos envolvidos. Colaborando com essa explanação, Saviani (2003) em defesa à pedagogia crítico-social, na qual aluno e professor se relacionam por meio do processo de ensino-aprendizagem, diz que é na prática social, tanto de professores como de alunos que se encontra o ponto inicial da ação pedagógica. Corroborando com essa perspectiva, Bulgraen (2010) diz que:

[...] o ponto de partida da ação pedagógica não seria a preparação dos alunos, cuja iniciativa é do professor (Pedagogia Tradicional) nem a atividade, que é de iniciativa dos alunos (Pedagogia Nova), mas seria a prática social comum a professor e alunos, considerando que do ponto de vista pedagógico há uma diferença essencial em que professor, de um lado, e os alunos de outro, encontram-se em níveis diferentes de compreensão (conhecimento e experiências) da prática social (BULGRAEN, 2010, p. 32)

Dessa maneira, mesmo o professor não sendo alguém visto como o único possuidor do saber e os alunos como mentes vazias que necessitam serem "preenchidas", é necessário que haja consciência de que cada um possui um papel dentro do processo de construção dos saberes. E assim, como aponta Fontana (2000), o docente precisa compreender sua posição no processo de ensino-aprendizagem, porém, sem deixar de levar em consideração que tanto o seu papel como o do estudante são importantes e que ambos devem atuar de maneira simbiótica para uma efetiva construção do conhecimento.

\section{DESAFIOS DA FORMAÇÃO DE PROFESSORES PARA A EDUCAÇÃO PROFISSIONAL TECNOLÓGICA}

As constantes mudanças no cenário mundial, sejam elas econômicas, políticas ou sociais dão aos professores cada vez mais atribuições no processo de construção dos indivíduos, de modo que esses necessitam constantemente se adaptar as demandas dos processos formativos. Diante dessa perspectiva está posto o contexto da EPT, sobre a qual 
existem muitas discussões acerca da necessidade de uma formação específica para os docentes que nela atuam (MALDANER, 2017; FONSECA, 2017).

Nesse contexto, discutir a formação docente não é uma tarefa simples, mesmo que seja feita de forma generalista. Quando se faz o recorte dessa discussão ao campo da EPT, surgem dificuldades bem acentuadas que necessitam de análises mais elaboradas. Com isso, elaboramos a alguns questionamentos importantes, tais como: "Quem está mais preparado para ser professor na EPT? Licenciados, bacharéis ou tecnólogos?", "O que é necessário para o docente estar preparado para a atuação na EPT?", "Há, de fato, a necessidade de uma formação específica para a docência na EPT? Se sim, qual formação seria essa?".

Primeiramente, é preciso dizer que todo professor deve possuir consciência de qual proposta de ensino a instituição da qual faz parte propõe e executa pois só assim ele será capaz de alinhar seu processo de formação às concepções de educação que the serão exigidas. Sendo assim, pode-se inferir que esse é o ponto de partida para o docente da EPT: conhecer a função política e social na qual esse campo do conhecimento está alicerçado, bem como, suas bases conceituais e ideológicas (SOUZA, 2013; FONSECA, 2017).

Por ser um campo do conhecimento que visa a formação ampla dos indivíduos, a EPT tem em seus quadros professores com as mais variadas bases formativas, sendo muitos deles licenciados (para atuação no núcleo básico) ou bacharéis/tecnólogos (para atuação no núcleo profissional). Sendo assim, não é possível afirmar que uma formação é mais adequada que a outra, tendo em vista que cada uma possui suas especificidades que vão muito além das vivências das salas de aulas durante a graduação, mas que dependem também das experiências individuais, conhecimentos prévios e contextos sociais nos quais esses educadores estiveram postos (CIAVATTA, 2014; FONSECA, 2017; RODRIGUES; FREITAS, 2016).

Por conseguinte, o que acaba sendo consenso entre os estudiosos do assunto, como Moura (2008), é que todos os profissionais envolvidos no âmbito da EPT devem possuir uma formação que os leve de encontro a quebra do tradicionalismo educacional, evitando a reprodução de uma educação definida por Freire (1996) como bancária.

Essa visão que Moura (2008) nos aponta está completamente alinhada as bases teóricas sobre as quais foi construída a EPT, como as concepções de omnilateralidade defendidas por Marx e Engles (MANACORDA, 2007), de formação humana integral discutida 
por Frigotto, Ciavatta e Ramos (2005) e de educação politécnica debatida por Saviani (1989). Tais concepções devem ser observadas, afinal se ao longo do processo de construção formativa do docente, no âmbito da EPT, não se assimilar esses pressupostos e compreendêlos como sendo o caminho que direciona a educação brasileira rumo a um projeto para a consolidação de uma escola sem dualidades (escola unitária gramsciana), então, não será possível que esses professores desempenhem suas funções de maneira adequada ao contexto da educação profissional.

Dessa maneira, para que seja possível a concretização da superação do tradicionalismo educacional e a materialização das bases conceituais da EPT nas instituições de ensino que a ofertam, se faz necessário que nos processos formativos dos seus docentes seja colocada como prioridade a constante articulação e integração entre as dimensões tecnicista e humanista.

Maldaner (2017) dialoga com os pensamentos de Moura (2008) quando trata esse processo de articulação a partir da divisão, em dois grades eixos, das bases de formação dos docentes da EPT. Segundo o autor,

O primeiro está relacionado com a área de conhecimento específica, adquirida na graduação, cujo aprofundamento é estratégico e deve ocorrer por meio dos programas de pós-graduação, principalmente stricto sensu. 0 outro eixo refere-se à formação didático político-pedagógica e às especificidades das áreas de formação profissional que compõem a esfera da EPT (MALDANER, 2017, p. 192)

Porém, o que se observa é uma imensa dificuldade dos docentes em entenderem do que se trata esse procedimento de articulação e, por conseguinte, de que maneira efetivá-lo nas salas de aulas, como aponta a fala de um professor da EPT em pesquisa realizada por Fonseca (2017):

A gente tem que entender que há umas articulações de formação e atuação profissional nessa área. Então, como a gente não consegue articular as condições via Universidade (que não é uma tarefa assim tão fácil, (...) rápida e objetiva), a gente precisa dentro da Educação Profissional Técnica e Tecnológica (...), os Institutos firmarem esse compromisso. (...) é uma pauta a ser seguida: formação específica para quem está atuando na Educação Profissional (FONSECA, 2017, p. 174) 
Diante desse cenário, existem autores que assinalam mecanismos de formação docente específica para a atuação na EPT, como Machado (2008) e Pereira (2004), que defendem os cursos de licenciatura exclusivos para a educação profissional, de modo que possam preencher a lacuna que se apresenta no que diz respeito a qualificação de docentes. Segundo Rodrigues e Freitas (2016), apoiados nos pensamentos de Pereira (2004), para que haja a formação do professor em EPT é necessário que se estabeleça, antes de tudo, a interrelação entre conhecimentos específicos da formação original do docente com "aqueles destinados ao domínio do que é específico à produção do conhecimento" (PEREIRA, 2004, p. 7), ou seja, com os conteúdos particulares da EPT.

Dessa forma, podemos concluir que não há uma formação ideal para que um docente atue ou não no campo da EPT. O que existem são necessidades de saberes específicos que carecem serem adquiridos ao longo dos processos de formação dos professores, sendo que as maneiras como essas competências serão alcançadas variam de acordo com as necessidades e com os contextos de cada indivíduo.

\section{DOCÊNCIA NA EDUCAÇÃO PROFISSIONAL E TECNOLÓGICA: A NECESSIDADE DE ALIAR TEORIA E PRÁTICA}

A EPT surgiu em um contexto político-social marcado pela desigualdade e norteada pela intenção de proporcionar uma educação que permitisse aos filhos da classe trabalhadora se prepararem para o posterior ingresso no mundo do trabalho, a fim de que pudessem garantir sua sobrevivência e a dos seus, pois os jovens pertencentes às classes menos favorecidas convivem com situações que lhes impõem a necessidade de complementar a renda familiar. Além disso, prima-se que essa modalidade de ensino oferte não só uma formação geral que sirva como arcabouço para a construção dos conhecimentos específicos desses futuros profissionais, mas também, com uma formação humanística que o habilite para uma atuação crítica na sociedade (MOURA, 2013; MOURA; LIMA FILHO; SILVA, 2015).

Nessa perspectiva, torna-se necessário que a articulação entre teoria e prática se manifeste diariamente nas práticas pedagógicas e educativas que os docentes aplicam 
durante as aulas, de modo que os estudantes adquiram consciência de que toda teoria pode gerar uma aplicação e, ao mesmo tempo, percebam que toda prática só é possível porque existe o conhecimento teórico (ARAÚJO; FRIGOTTO, 2015).

Existem muitas maneiras para conceber essa articulação entre teoria e prática, porém, é necessário que façamos um agrupamento em duas categorias principais: a dicotômica ou dualística e a unitária. A primeira remete as aplicações práticas que resultam dos conhecimentos teóricos negando que a prática possa ser geradora de algum conhecimento; enquanto que a segunda, aponta que tanto a teoria quanto a prática são capazes de produzir saberes de maneira simultânea e recíproca (CANDAU, 1999).

Seguindo com a discussão, é possível dizer que todos os membros que constituem a instituição de ensino que oferece a EPT (estudantes, docentes, técnicos administrativos, gestores, entre outros...) devem estar envolvidos com essa proposta de ensino com a intenção de romper com essa dualidade estrutural que insiste em permear o currículo da educação (MOURA, 2008)

É indispensável salientar que para que os docentes estabeleçam uma relação teóricoprática efetiva, durante os procedimentos de ensino e de aprendizagem, a instituição da qual façam parte precisa dispor de um currículo que permita tal articulação, afinal as práticas dos docentes devem ser um reflexo daquilo que as matrizes curriculares e projetos pedagógicos dos cursos lhes propõem.

O currículo, além de ser construído levando em consideração as práticas sociais do contexto em que os indivíduos estão inseridos, deve proporcionar um conjunto de conteúdos e experiências ao aluno para que haja a concretização dos objetivos da aprendizagem, não devendo ser algo imutável ou engessado e que não permita mudanças em seu conteúdo. Para isso, é imprescindível que seja praticado de maneira associada às práticas políticas e administrativas, condições estruturais, materiais e à formação docente (MACHADO, 2009)

Por conseguinte, podemos afirmar que assim como os estudantes necessitam da articulação teórico-prática para sua formação plena enquanto cidadãos, os professores e seus saberes também são moldados pela mediação dessa relação. De um lado, a teoria manifesta sua relevância por permitir que os profissionais aprofundem seus conhecimentos em antigas e novas temáticas; de outro, é por meio da prática em sala de aula que os 
docentes se deparam com a realidade daquele contexto no qual a instituição de ensino e seus estudantes estão inseridos, fato que os impele a buscarem nos conhecimentos teóricos meios para a materialização prática dos saberes com o intuito de melhorarem a aprendizagem dos alunos.

Nessa perspectiva, Souza, Torres e Dantas (2017) refletem sobre o fazer docente e as implicações das relações teórico-práticas no contexto da educação profissional, dizendo que:

[...] o educador somente poderá ensinar quando aprender na prática o que deve fazer e, para isso, ter conhecimento, que é adquirido com diálogo e troca de experiências. Compreender o processo de ensino e aprendizagem, apesar da formação oferecida em sala de aula ser fundamental, só ela não é suficiente para preparar os alunos para o exercício de sua profissão. Faz-se necessário a inserção na realidade do cotidiano escolar com a prática pedagógica. (SOUZA; TORRES; DANTAS, 2017, p. 5)

Portanto, é possível inferir que a atuação do professor deve ser pautada na teoria e na prática, para que ele contribua de maneira concreta com a formação profissional dos alunos. Seguindo essa perspectiva e tomando por base as contribuições de Kuenzer e Grabowski (2006), compreende-se que a EPT exige a formação de um novo tipo de docente, que seja habilitado para produzir situações de ensino e aprendizagem que possam despontar nos indivíduos a capacidade de produção intelectual, a partir da qual os sujeitos serão capazes de lidar com as problemáticas da vida social e do mundo do trabalho. Diante disso, é possível afirmar que o docente da EPT deve ser um profissional capacitado para gerar reflexões nos estudantes, de modo que os aprendizes desenvolvam uma visão ampla do ambiente que os cerca e dos contextos nos quais estão inseridos, analisando-os de maneira crítica (MACHADO, 2008).

\section{CONSIDERAÇÕES FINAIS}

O mundo contemporâneo passa por constantes mudanças político-sociais que impõem aos professores cada vez mais funções no que concerne aos processos de formação dos sujeitos. Esse fato exige desses profissionais o desenvolvimento de habilidades e competências que, muitas vezes, não foram adquiridas ao longo das suas graduações, 
necessitando que eles busquem um aprofundamento nas suas aptidões a fim de construírem uma formação docente sólida que Ihes permita o desempenho efetivo de suas atribuições.

A EPT é, reconhecidamente, um campo do conhecimento que exige dos seus docentes uma visão de educação que vai além das concepções tradicionais. Porém, há uma constante discussão sobre qual seria a formação mais adequada para que um docente possa atuar na área, no entanto, não há um consenso a respeito desse assunto entre aqueles que se debruçam sobre essa discussão.

Entretanto, parece claro que os professores devem, a princípio, apreenderem em quais bases teóricas e filosóficas essa área da educação está pautada, para que possam alinhar seus processos de formação e qualificação profissional aos mesmos ideais e objetivos da EPT, de modo que sejam capazes de compreender que essa proposta de ensino é voltada para a formação ampla dos sujeitos, ou seja, direcionada para a emancipação e também para a quebra da dualidade estrutural na educação.

Além das competências adquiridas na formação básica desses docentes e a consciência sobre qual tipo de educação a EPT oferta, ao professor também é exigido que saiba realizar a articulação entre teoria e prática, de modo que seja capaz de inspirar nos alunos a consciência de que conhecimentos teóricos e específicos são elementos indissociáveis para a formação social e profissional dos indivíduos.

\section{REFERÊNCIAS}

ARAUJO, R. M. L.; FRIGOTTO, G. Práticas pedagógicas e ensino integrado. Revista Educação em Questão, Natal, v. 52, n. 38, p. 61-80, 2015.

ARROYO, M. G. Ofício do mestre: imagens e auto-imagens. 14. ed. Petrópolis: Vozes, 2013.

BULGRAEN, V. C. O papel do professor e sua mediação nos processos de elaboração do conhecimento. Revista Conteúdo, Capivari, v. 1, n. 4, p.30-38, 2010. ISSN 1807-9539.

CANDAU, V. M.; LELIS, I. A. A Relação Teoria-Prática na Formação do educador. In: CANDAU, V. M (Org.). Rumo a uma Nova Didática. 10 ed. Petrópolis: Vozes. 1999. p.56-72. ISBN 97885-32604-34-0 
CIAVATTA, M. Ensino Integrado, a Politecnia e a Educação Omnilateral: por que lutamos?. Revista Trabalho \& Educação, v. 23, n. 1, p. 187-205, 2014.

FONSECA, C. M. F. Formação e Saberes Docentes Na Educação Profissional: Um Relato De Experiência. Revista Brasileira da Educação Profissional e Tecnológica, v. 1, n. 12, p. 170, 2017.

FONTANA, R. A. C. Mediação pedagógica na sala de aula. 3. ed. Campinas: Autores Associados, 2000.

FREIRE, P. Pedagogia da autonomia: saberes necessários à prática educativa. São Paulo: Paz e Terra, 1996.

FRIGOTTO, G. A gênese das teses do Escola sem Partido: esfinge e ovo da serpente que ameaçam a sociedade e a educação. In: FRIGOTTO, G. (org). Escola sem Partido: esfinge que ameaça a educação e a sociedade brasileira. Rio de Janeiro: UERJ, LPP, 2017. p. 17-34.

FRITOTTO, G.; CIAVATTA, M.; RAMOS, M. Ensino Médio Integrado: concepção e contradições. São Paulo: Cortez, 2005.

GIL, A. C. Como elaborar projetos de pesquisa. 4. ed. São Paulo: Atlas, 2007.

KUENZER, A. Z.; GRABOWSKI, G. Educação profissional: desafios para a construção de um projeto para os que vivem do trabalho. Perspectiva, Florianópolis, v. 24, n. 01, p. 297-318, 2006.

LEIVA, J. S.; SINÉSIO, L. E. M; CORRÊA, .ação Profissional e Tecnológica, v. 1, n. 16, p. 1-24, 2019. ISSN - 2447-1801.

MACHADO, Lucília R. S. Diferenciais inovadores na formação de professores para a Educação Profissional. Revista Brasileira da Educação Profissional e Tecnológica, Brasília, v. 1, n. 1, p. 8-22, 2008.

Ensino médio e técnico com currículos integrados: propostas de ação didática para uma relação não fantasiosa: propostas de ação didática para uma relação não fantasiosa. In: MOLL, J. et al (org.). Educação Profissional e Tecnológica no Brasil Contemporâneo: desafios, tensões e possibilidades. Porto Alegre: Artmed, 2009. p. 80-95.

MALDANER, J. J. A formação docente para a educação profissional e tecnológica: breve caracterização do debate. Revista Brasileira da Educação Profissional e Tecnológica. v. 2, n. 13, p. 182-195, 2017. ISSN - 2447-1801.

MANACORDA, M. A. Marx e a pedagogia moderna. 3. ed. Campinas: Alínea, 2007.

MIZUKAMI, M. G. N. Ensino: as abordagens do processo. São Paulo: EPU, 1986. 
MORAIS, J. K. C; HENRIQUE, A. L. S. O professor licenciado na educação profissional: quais os saberes docentes que alicerçam seu trabalho?. Revista Brasileira da Educação Profissional e Tecnológica, v. 1, n. 7, p.66 - 74, 2014.

MOURA, D. H. A formação de docentes para a educação profissional e tecnológica. Revista Brasileira de Educação Profissional e Tecnológica/Ministério da Educação, Secretaria da Educação Profissional e Tecnológica. v.1, no 1, p. 23-38, 2008. Brasília: MEC, SETEC, 2008. Anual.

Ensino médio integrado: subsunção aos interesses do capital ou travessia para a formação humana integral?. Educação e Pesquisa - Revista da Faculdade de Educação da USP, v. 39, p. 705-720, 2013.

MOURA, D. H.; LIMA FILHO, D. L.; SILVA, M. R. Politecnia e formação integrada: confrontos conceituais, projetos políticos e contradições históricas da educação brasileira. Revista Brasileira de Educação, Rio de Janeiro, v. 20, n. 63, p.1057-1080, 2015. ISSN: 1413-2478.

NÓVOA, A. Currículo e docência: a pessoa, a partilha, a prudência. João Pessoa: UFPB, 2004.

PEREIRA, L. A. C. A formação de professores e a capacitação de trabalhadores da educação profissional e tecnológica. In: Fórum de Educação Profissional (Anais), 2004.

RODRIGUES, M. R. S. L.; FREITAS, M. C. S. Formar-se para ensinar: experiência de um Instituto Federal. Revista Brasileira da Educação Profissional e Tecnológica, v. 2, n. 11, p. 51, 2016. ISSN 1983-0408.

SAVIANI, D. Escola e Democracia. 36. ed. Campinas: Autores Associados, 2003.

Sobre a concepção de politecnia. Rio de Janeiro: EPSJV/Fiocruz. 1989.

SOUZA, A. L. L. Formação inicial e continuada de professores para a educação profissional: a política e a produção do conhecimento para a emancipação. In: MOURA, D. H. Produção do conhecimento, políticas públicas e formação docente em educação profissional. São Paulo: Mercado das letras, 2013, p. 385-407.

SOUZA, D. F. D.; TORRES, M. J. F.; DANTAS, S. F. Percepção da relação teoria e prática no trabalho docente: um estudo com professores da área da saúde. Revista Brasileira da Educação Profissional e Tecnológica, v. 1, n. 12, p. 125-139, 2017. ISSN 2447-1801.

TARDIF, M. Saberes docentes e formação profissional. 5. ed. Petrópolis: Vozes, 2005

VERDUM, P. Prática pedagógica: o que é? O que envolve? Revista Educação por Escrito, v. 4, n.1, p. 91-105, 2013.

YIN, R. K. Pesquisa qualitativa: do início ao fim. Porto Alegre: Penso, 2016. 